\title{
Impact of Informing Overweight Individuals about the Role of Genetics in Obesity: An Online Experimental Study
}

\author{
Natalie C. Lippa Saskia C. Sanderson \\ Department of Genetics and Genomic Sciences, Icahn School of Medicine at Mount Sinai, New York, N.Y., USA
}

\section{Key Words}

Obesity genetics - Overweight individuals - Online survey .

Genetic information

\begin{abstract}
Background/Aims: Increasing public awareness of obesity genetics could have beneficial or harmful effects on overweight individuals. This study examined the impact of genetic information on weight-related cognitions as well as interest in personalized genetic information about obesity among overweight individuals. Methods: Online survey respondents $(n=655)$ were randomly assigned to read either genetic, gene-environment, or nongenetic obesity causal information. Fifty-two percent of the participants were female, $82.4 \%$ were White, $45 \%$ had an annual income of USD $<40,000$, and the mean BMI was 32.5. Internalized weight stigma was measured using the Weight Bias Internalization Scale. Results: Participants in the genetic and gene-environment conditions were more likely to believe genetics increase obesity risk than participants in the nongenetic condition (both $\mathrm{p}<0.05$ ); however, they did not differ regarding internalized weight stigma. Sixty-four percent of the participants expressed interest in receiving personalized genetic information about their obesity risk. Conclusion: Dissemina-
\end{abstract}

tion of information about obesity genetics may have neither a beneficial nor a harmful impact on how overweight individuals perceive themselves. Some overweight individuals may be interested in receiving personalized genetic information. The actual effects of obesity genetic information being incorporated into public health messages and of personalized genetic information on obesity prevention and treatment interventions remain to be seen.

(c) 2013 S. Karger AG, Basel

\section{Introduction}

Obesity continues to be a major public health issue, with over $60 \%$ of the US population being either overweight or obese [1]. It is not yet clear whether or how new discoveries in obesity genomics research might aid public health initiatives to decrease the prevalence of obesity or its health and social consequences. In addition to the well-documented dire health implications of obesity itself, the stigmatization of obese individuals in society is an important problem that has serious consequences, and which is increasing in prevalence [2]. Stigma has been defined as the result of a process in which 5 interrelated components combine to generate stigma: (1) the identifi-

\section{KARGER}

E-Mail karger@karger.com

www.karger.com/hhe
(C) 2013 S. Karger AG, Basel

0001-5652/13/0754-0186\$38.00/0
Saskia C. Sanderson

Department of Genetics and Genomic Sciences

Mount Sinai School of Medicine, One Gustave L. Levy Place

Box 1497, New York, NY 10029 (USA)

E-Mail saskia.sanderson@mssm.edu 
cation and labeling of human differences; (2) stereotyping and linking the labeled person to undesirable characteristics; (3) separating 'them' - the stigmatized group from 'us'; (4) the stigmatized group experiencing discrimination and loss of status, and finally (5) the exercise of power (that is, without power over the specified group, stigmatization is not possible) [3]. Many groups in society experience stigma based on a range of characteristics and conditions, including race, AIDS, mental illness, and obesity.

Collectively, there is evidence that stigmatization of groups within society, regardless of the specific type of stigma, may have a powerful impact on population health inequalities [4]. Within the domain of mental illness, research has suggested that the effects of mental illness stigma include low self-esteem $[5,6]$ and depression $[6]$, and internalized mental illness stigma has been associated among affected patients with lower levels of hope, empowerment, self-esteem, self-efficacy, quality of life, social support, and treatment adherence [7].

There is also compelling evidence that obese individuals are highly stigmatized and encounter many forms of prejudice and discrimination because of their weight. Obesity stigma can have significant negative effects on both the emotional and physical well-being of obese individuals. Negative attitudes towards those who are overweight can cause discrimination in employment settings, health-care facilities, and educational institutions [2]. Health-care providers demonstrate less emotional rapport with obese patients [8]. The stigmatization of obese individuals by health-care professionals leads to overweight individuals avoiding health-care appointments, which has clear potential adverse consequences for their health [9]. As with mental illness stigma, individuals who experience weight stigma are at an increased risk of negative psychological effects such as depression and lower self-esteem as well as more body dissatisfaction [10-12]. Experiences with weight stigma are also associated with negative health behaviors such as avoidance of dieting and exercise [11-13].

\section{Internalized Weight Stigma}

As with other types of stigma, obesity stigma can result in overweight and obese individuals internalizing this damaging way of thinking and applying it to themselves, resulting in what has been labeled 'internalization of antifat attitudes' or 'internalized weight stigma' $[14,15]$. Internalized weight stigma has been defined as the internalization of negative social messages about being overweight [16]. Drawing on Livingston's and Boyd's [7] definition of internalized mental illness stigma, internalized weight stigma can also be defined as a process by which individuals endorse stereotypes about obesity, consider stereotypes to be self-relevant, anticipate social rejection, and believe they are a devalued member of society.

For most stigmatized groups (e.g. groups defined by race, religion, or gender), group members often find comfort from other members of the stigmatized group. However, it seems that obesity stereotypes are different in that obese individuals often endorse anti-fat attitudes or fat stereotypes themselves $[15,17]$. For example, in one online survey, obese participants showed an implicit stereotyping of fat people as lazy compared to thin people [15]. This suggests that the support network that exists for members of other stigmatized groups may not exist in the same way in the obese population, which may lead to poorer mental health and coping mechanisms [18].

Recently, a highly internally consistent questionnaire to concisely measure internalized weight stigma in overweight and obese individuals has been introduced. The Weight Bias Internalization Scale (WBIS) was developed using an internet sample of individuals recruited through online community discussion groups. Validity testing suggested that internalized weight stigma is a construct that is related but distinct from anti-fat attitudes, and that it is associated with lower self-esteem, certain mood states, greater body image concern, greater eating disturbance including more frequent binge eating, and a higher level of drive for thinness [16].

Internalized weight stigma has been demonstrated to have numerous adverse psychological, behavioral, and physical consequences. For example, in one US study [19], individuals who belonged to a national nonprofit weight loss organization were asked to list stereotypes of overweight/obese people and report if the stereotypes were true or false. The most common perceived stereotypes were that overweight people are lazy, unintelligent, and unhygienic and that they overeat and binge. Participants who reported the stereotypes as true were more likely to cope with stigma by refusing to diet compared with those who reported them to be false. In addition, internalized weight stigma was associated with binge eating behaviors, suggesting that overweight and obese persons who internalize stereotypes may be more likely to binge eat. Internalized weight stigma may therefore increase unhealthy eating behaviors and reduce motivation to lose weight. Individuals who internalize obesity stigma may have less confidence in their ability to successfully lose weight, possibly due to an increase in self-blame [19]. 
Similarly, in a study of overweight 11-year-old girls [18], those who internalized fat stereotypes reported lower general self-worth, lower perceived attractiveness, and more maladaptive eating attitudes than overweight girls who did not internalize fat stereotypes. In addition, being overweight and endorsing fat stereotypes at the age of 9 years was associated with higher maladaptive eating attitudes at the age of 11 years, suggesting that girls who internalize fat stereotypes and subscribe to the perceived controllability of their group membership may adopt maladaptive eating behaviors in an effort to control their weight and remove themselves from the stereotyped group [18].

The observation that many of the harmful effects of obesity stigma arise because of obese individuals turning that stigma on themselves and internalizing it is important. It suggests that harms from obesity stigma could be reduced by addressing both obesity stigma among the protagonists and internalized obesity stigma among the stigmatized. This was suggested by the authors of a study [20] in which overweight and obese individuals who reported experiencing more frequent weight stigma from others (e.g. from family members, from doctors, and in employment settings) also reported greater avoidance of exercise and exercise-related experiences. Interestingly, there was an interaction effect with internalized anti-fat attitudes and societal standards in that individuals who experienced obesity stigma and, at the same time, reported internalizing that stigma demonstrated yet higher levels of avoidance [20]. This highlights that it is not always stigma per se that causes the harmful outcomes but often the internalization of that stigma. It also highlights the potentially important role of reducing internalized obesity stigma in addition to obesity stigma more generally as part of efforts to reduce obesity and related harms. Overall, evidence is accumulating highlighting that internalized weight stigma among overweight and obese individuals is an important issue that needs to be tackled.

\section{Genomics and Internalized Weight Stigma}

Recent advances in obesity genomics research [21] could have potentially major positive, or negative, implications for internalized weight stigma-reducing efforts. Attribution theory [22] suggests that weight stigmatization emerges from attributions about the causes of obesity, where perceptions that body weight is within personal control worsen attitudes towards obese persons. Increasing public dissemination of new research findings illustrating that obesity has a significant genetic component could increase awareness of an important uncon- trollable element of obesity, thereby potentially reducing obesity stigma among healthy weight people and internalization of weight stigma among overweight and obese people.

Alternatively, the increasing 'geneticization' of individual traits such as obesity could have negative implications. The eugenics movement in the late 19th and early 20th century is a painful reminder that overemphasis on genetic aspects of human traits and conditions can lead to devastating policies being implemented, such as marriage restrictions, sterilization, and even extermination [23]. In the literature on mental illness stigma, Phelan [23] draws on the definition of stigma from Link and Phelan [3] to further posit how increased genetic emphasis could increase rather than decrease stigma: by increasing the 'us versus them' distinction as saying that a problem is 'in your genes' could reduce the likelihood that people will think that status can be changed, and by increasing intimate social distance (e.g. by reducing chances that others will choose to marry or have children with the 'labeled' individual). The empirical evidence so far on how this actually plays out for mental illness is mixed [23-25].

In research focused on obesity, a handful of studies have examined relationships between belief in genetic causation of weight and obesity stigma. One cross-sectional telephone survey of 1,000 individuals found that higher obesity stigma was negatively associated with attribution to heredity and positively associated with attribution to individual behavior [26]. Studies that have tried to reduce obesity stigma among general populations (i.e. individuals not selected for being overweight or obese) using genetic information have shown inconsistent results [22, 27-31]. In an innovative study using virtual reality, medical students who interacted with an obese virtual patient after reading information about genetic mechanisms in obesity exhibited significantly less negative stereotyping of the patient than a control group who did not read genetic information [32]. In related research, the results of a randomized controlled trial indicated that obese individuals with a family history of obesity who were provided with personalized genetic information about obesity showed reductions in self-blame [33]. No adverse effects of the genetic information on outcomes such as self-efficacy or self-control were observed [34]. Genetic causal beliefs were higher among individuals with a familial obesity risk but were unrelated to weight regulation beliefs or any other weight-related outcomes [35].

Obesity stigma and internalized weight stigma are, by definition, directly and indirectly shaped by cultural and 
societal norms. Mass media play a key, albeit bidirection$\mathrm{al}$, role in the shaping of these weight-related norms. Relatedly, most people in the general population will learn about new genomic discoveries, including those regarding obesity, via mass media sources such as television, newspapers, online news articles, and social media [36]. At this moment in time when genomic research on complex traits like obesity is advancing at a rapid pace, it is timely to explore whether and how news-like information might impact obesity stigma and internalized weight stigma. Only one study to date has attempted to directly reduce internalized weight stigma: this study successfully reduced internalized stigma among overweight participants via an intensive 1-day workshop, but the study did not focus on genetic aspects of obesity $[37,38]$. At a population health level, the time and resources required for such an intensive intervention with patients is unrealistic, except perhaps in extreme clinical cases.

The effects of public dissemination of genetic information about obesity on internalized weight stigma and related cognitions among overweight/obese populations remain to be seen. To our knowledge, no study has assessed the impact of reading news article-style information about obesity genetics on internalized weight stigma in overweight/obese populations. Although a single article about obesity genetics is perhaps unlikely to have a long-term impact on stigma in the real world, if such an article could be demonstrated to have an immediate albeit short-lived impact in an experimental setting, this would have significant implications for the future as genomic discoveries about obesity and their public dissemination accumulate.

\section{The Present Study}

For the present study, we therefore developed written information about obesity that was more detailed than that used in previous research [28], but which was still written broadly in the style of a brief news article. A general population sample of individuals was then recruited to complete an online survey, and respondents were randomly assigned to receive information about genetic causes, nongenetic causes, or gene-environment interaction causes of obesity. The latter information type was included given it more accurately reflects the complex multifactorial gene-environment interactions involved in the etiology of obesity [39]. We also randomly assigned participants to either receive or not receive behavioral advice to explore whether providing individuals with behavioral advice would influence how participants responded to the causal information type.

Informing Overweight Individuals about the Role of Genetics in Obesity
We assessed obesity stigma among participants who perceived themselves not to be overweight and internalized weight stigma among participants who perceived themselves to be overweight, and analyzed the two samples separately. No differences in obesity stigma were found between the experimental groups among the nonoverweight participants; we have previously published these results elsewhere [27]. Internalized weight stigma is related to, but distinct from, obesity stigma [16], and it is important that efforts to reduce the harmful effects of obesity stigma are implemented both among the protagonists and the stigmatized [20]. In the present paper, we therefore now report the results on internalized weight stigma among the overweight/obese subsample. Because of concerns about the potential for genetic information to reduce people's perceived control over their weight or behavior, we also explored the potential impact of genetic information on control-related cognitions, specifically perceived control over weight loss, diet, and exercise and perceived response-efficacy (i.e. confidence that changing diet or exercise can help weight loss) as well as how genetic information might affect overweight people's self-image or self-esteem. We also explored whether overweight/obese individuals were interested in receiving personalized genetic information about their obesity risk and that of their children, given this could have significant implications for future efforts to incorporate genetic information into obesity prevention, treatment, and management.

\section{Study Aims}

Our primary aim was to examine whether overweight/ obese individuals report differing levels of internalized weight stigma depending on whether or not they receive genetic information about the causes of obesity. We hypothesized that genetic causal information would be associated with lower levels of internalized weight stigma than nongenetic information, and that this would be mediated by genetic causal beliefs. We also hypothesized that internalized weight stigma in the gene-environment information group would fall between the other two groups.

Our second aim was to examine whether overweight/ obese people who received genetic information about the causes of obesity would report differing levels of perceived control over their weight, perceived control over related behaviors, and self-esteem than those who received nongenetic information.

Our third aim was to explore whether factors such as maladaptive eating attitudes and low self-esteem were associated with internalized weight stigma. 


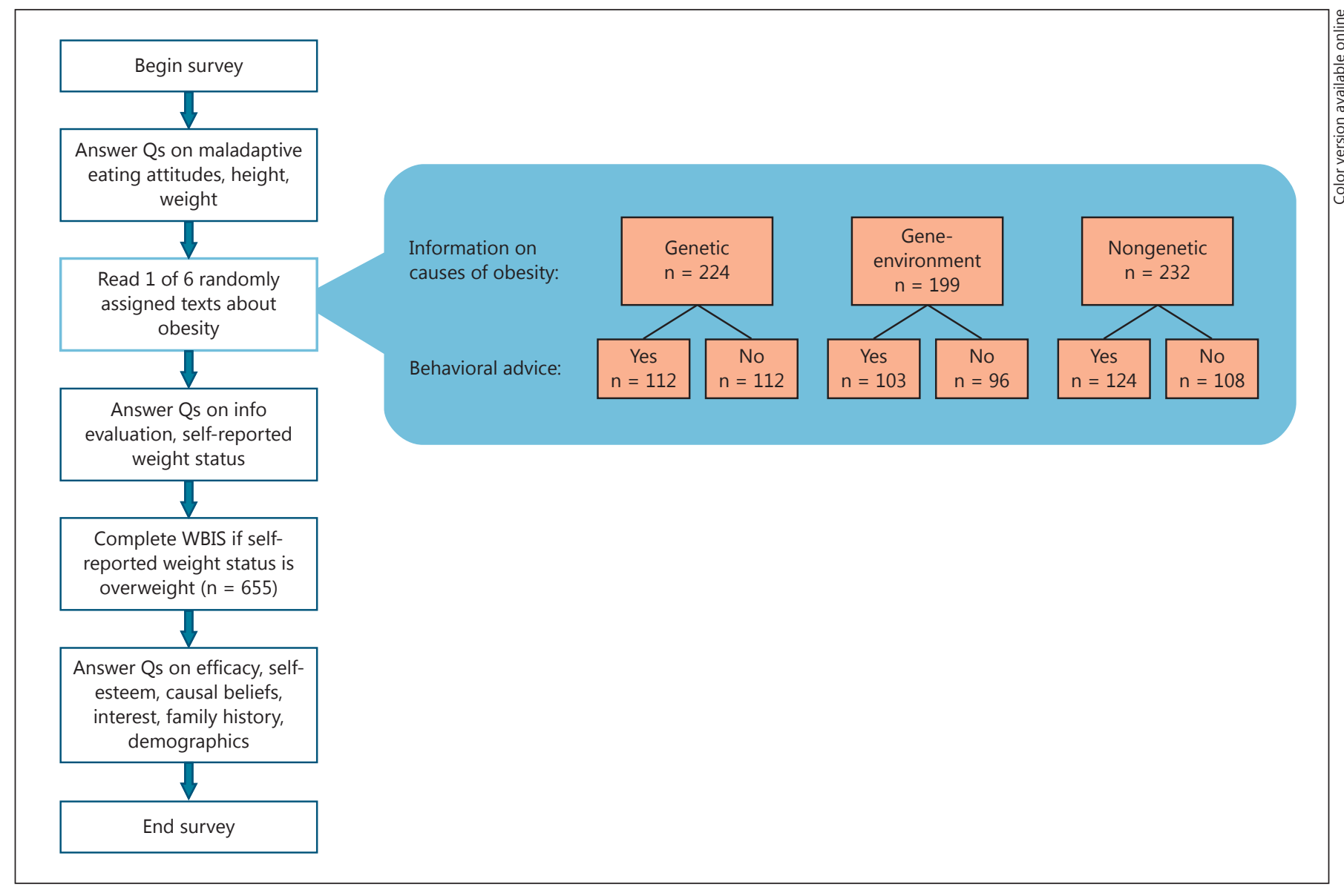

Fig. 1. Study design and participant randomization.

Our fourth aim was to examine whether there is a moderating effect of behavioral advice on the associations between genetic causal information and control-related outcomes. We hypothesized that individuals who received genetic information in addition to behavioral advice would report higher levels of perceived control than individuals who received genetic information without behavioral advice.

Our final aim was to explore whether overweight/ obese individuals were interested in receiving personalized genetic information about their obesity risk.

\section{Methods and Procedures}

Study Design, Participants, and Recruitment

An online survey of individuals in the general population was conducted using SurveyMonkey. Participants were randomly assigned to receive one of the three different types of information about the causes of obesity and to either receive or not receive behavioral advice regarding weight management (fig. 1). Thus, this study used a $3 \times 2$ experimental design: obesity causal information type (genetic vs. gene-environment vs. nongenetic) $\times$ behavioral advice (yes vs. no). The study was reviewed and determined to be exempt from the approval of the Institutional Review Board at the Icahn School of Medicine at Mount Sinai, New York (N.Y., USA).

Participants were recruited through the online market research group Survey Sampling International (SSI). Male and female participants over the age of 18 years were eligible for recruitment. SSI provided eligible respondents with a link to the survey. In addition, SSI used a confidential identification number (which they did not share with the investigators) to provide respondents with an incentive to complete a survey. The incentive for all participants was a quarterly drawing for USD 25,000. Every respondent who completed the survey during the given quarter was entered into the contest. Another incentive applied to participants who were between the ages of 18-23 years. These participants were offered 300 points (which is the equivalent to USD 3) to complete the survey.

Because the wording of the WBIS [16] assumes that the respondents perceive themselves to be overweight (the measure includes 
items such as 'Whenever I think a lot about being overweight, I feel depressed' and 'As an overweight person, I feel that I am just as competent as anyone'), it would have been hard for people who did not perceive themselves to be overweight to answer these questions. Participants were therefore asked to indicate whether they believed themselves to be overweight or not, and only individuals who self-identified as 'slightly overweight' or 'very overweight' completed the WBIS [16]. Individuals who did not believe themselves to be overweight were instead asked to complete the Fat Phobia Scale-Short Form (FPS-S) [40]; we have previously published the results examining the effects of the experimental information on nonoverweight individuals elsewhere [27].

\section{Experimental Conditions}

After entering the online survey, participants answered some initial questions regarding eating attitudes, height, and weight (described below) and were then randomly assigned to one of the written information experimental conditions (each comprising a total of 226-330 words). All participants received identical information about the risk and consequences of obesity. One third of the participants then received genetic information, one third received nongenetic (environment) information, and one third received gene-environment interaction information about the causes of obesity. Half of the participants also received behavioral advice about how to reduce obesity risk.

In brief, the genetic information contained information about twin studies, heredity, and genetic transmission of obesity-relevant genes. The nongenetic (environment) information contained information about large portion sizes, easy access to nutrient poor and high-calorie foods, and conditions that favor sedentary behavior. The gene-environment interaction information contained information from both the genetic and environmental information sheets and how genes interact with the environment. Finally, the behavioral advice contained information about eating healthier and exercising more frequently. The full wording of all components of the written experimental information used in this study can be found in Lippa and Sanderson [27]. Information for the content of the experimental conditions was compiled from the scientific literature [41-44], a CDC website about obesity [45], and an online news article from Newsweek about obesity and genetics [46]. Participants were then asked to complete the rest of the questionnaire.

\section{Measures}

Measures assessed before manipulation (i.e. before participants were randomized to the experimental conditions) included: maladaptive eating attitudes, self-reported height, and self-reported weight. Measures assessed after manipulation (i.e. after participants were randomized to the experimental conditions) included: demographics, family history of obesity, perceived weight status, evaluation of the information they had just read, causal beliefs about obesity, internalized weight stigma, self-esteem, and interest in receiving personalized genetic information about obesity risk (fig. 1).

\section{Demographic and Weight-Related Variables}

Demographic characteristics were assessed by asking participants to report their age, gender, highest level of education completed, annual household income, ethnicity, and relationship status.

Informing Overweight Individuals about the Role of Genetics in Obesity
For weight-related variables, BMI was calculated from participant self-reports of their height and weight, and BMI categories were assigned based on CDC guidelines [45]. Participants were excluded if their calculated BMI was unrealistically low (less than 16) or unrealistically high (over 55). Participants were also asked to indicate whether they perceived themselves to be 'very underweight', 'slightly underweight', 'healthy weight', 'slightly overweight', or 'very overweight'. Participants who reported they were very underweight, slightly underweight, or healthy weight were excluded from the present analysis. Family history was assessed by asking participants whether they thought any of their first-degree relatives (mother, father, siblings, and children) were overweight. The total number of first-degree relatives that were overweight was calculated for each participant.

To assess maladaptive eating attitudes, we used selected items from the Eating Disorder Examination Questionnaire (EDE-Q) [47], which has 4 subscales: restraint, weight concern, shape concern, and eating concern. Alpha reliability scores in the present sample of 655 individuals were 0.86 for restraint, 0.89 for shape concern, and 0.79 for weight concern. Eating concern was assessed using only one question and so no alpha reliability score was calculated. More detail on the EDE-Q items used in this study can be found in Lippa and Sanderson [27].

For the evaluation of the information, participants were asked to rate whether the experimental information they had just read about obesity was 'easy to read', 'relevant to me', 'useful to me', and (4) 'provided me with new information' (5 response options from 'strongly disagree' to 'strongly agree').

\section{Causal Beliefs about Obesity}

Causal beliefs about obesity were assessed using 10 items adapted from the revised Illness Perception Questionnaire (IPQ-R) [48]. Participants were asked on a 5-point Likert scale how much they agreed or disagreed that each of the following causes obesity: 'Stress or worry', 'A germ or virus', 'Diet or eating habits', 'Chance or bad luck', 'Hereditary - it runs in families', 'Overwork', 'Ageing', 'The environment', 'Lack of exercise', and 'A person's genes' (5 response options for each from 'strongly disagree' to 'strongly agree').

\section{Internalized Weight Stigma}

The 11-item WBIS was used to assess internalized weight stigma [16]. The participants rate the statements in the WBIS on a 7-point scale from 'strongly disagree' to 'strongly agree'. We checked whether the scale items were measuring a single construct in our sample using principle component analysis with VARIMAX rotation. The items actually clustered around two components (as defined by eigenvalues $>1$ ). In fact, Durso and Latner [16] in their original study introducing the WBIS similarly found that the items formed two factors, and component structure was set for one factor, based on examination of the scree plot, the majority of the variance being accounted for by the first factor, and the hypothesized unidimensional structure. Subsequent factor loadings suggested that the items could in fact be represented by a single factor. In our study, component 1 explained $56.0 \%$ and component 2 only accounted for $10.0 \%$ of the variance in scores. We found that all except the first item loaded well on to a single factor with eigenvalues $>0.4$. This, combined with examination of the scree plot, suggested that the items could be represented by a single factor in our study. Although we could have excluded item 1 due to its low fac- 
tor loading, we retained it in order to keep the scale consistent with the original scale. Cronbach's a was 0.92 , indicating good reliability.

Perceived Control

Perceived control over weight loss was assessed with 2 items adapted from Ajzen [49] and previous research [50]: 'I am confident that if I tried to lose weight in the next 3 months I could keep to it' and 'I am confident that I could lose weight if I wanted to' (5 response options for each from 'strongly disagree' to 'strongly agree') (eigenvalues $>0.80$, Cronbach's alpha 0.82 ). Perceived control over diet was assessed with the same 2 items but with 'eat a healthy diet' replacing 'lose weight' (eigenvalues $>0.80$, Cronbach's alpha 0.81). Perceived control over exercise was assessed with the same 2 items but with 'exercise more' instead of 'lose weight' (eigenvalues $>0.80$, Cronbach's alpha 0.80 ).

Perceived Response Efficacy

Diet response efficacy was assessed with 3 items adapted from Witte et al. [51]: 'Eating a healthy diet is effective in preventing obesity', 'Eating a healthy diet works in preventing obesity', and 'If I eat a healthy diet, I am less likely to become obese' (5 response options from 'strongly disagree' to 'strongly agree') (eigenvalues $>0.4$, Cronbach's alpha 0.88). Exercise response efficacy was assessed with the same 3 items but with 'exercising more' replacing 'eating a healthy diet' (eigenvalues $>0.4$, Cronbach's alpha 0.92).

Self-Esteem

Self-esteem was assessed using a single-item measure [52]: 'I have high self-esteem' (response options from 1 'not very true of me' to 5 'very true of me'). This measure has shown strong convergent validity for men and women, different ethnic groups, college students as well as community members with the multi-item Rosenberg Self-Esteem Scale [53].

Interest in Receiving Personalized Genetic Information about Obesity

Interest was assessed as follows: 'Please imagine that you have taken part in a genetic research study, and you are told that you can find out your personal genetic results if you want them. These genetic results can give some information about whether you are at increased or decreased risk of developing obesity, but they can't tell you definitely whether you will or will not become obese. Would you want to find out your personal genetic risk results for obesity?' (5 response options from 'no definitely not' to 'yes definitely'). A second question asked whether the participants would want to find out their child's personal genetic risk results for obesity. The results are reported for the proportions of participants who responded 'yes probably' or 'yes definitely' to these questions, i.e. the proportions of participants who reported that they would be interested.

\section{Statistical Analyses}

Demographic and weight-related characteristics (gender, age, education, income, ethnicity, BMI, family history, relationship status, and perceived weight status) were described using frequencies, means, and standard deviations, and compared between the experimental groups using $\chi^{2}$ tests to check for potential confounders. For the main analyses comparing the primary and secondary variables (causal beliefs, internalized weight stigma, perceived control, response efficacy, and self-esteem) between the experimental groups, we used Kruskal-Wallis tests because all of the outcome variables were non-normally distributed. We created two dummy variables (the first representing the causal information type and the second representing the behavioral advice condition), so that we could examine whether there were significant differences between the three causal information type groups combined on the outcome variables as well as between the two behavioral advice groups; this was done using Kruskal-Wallis tests. For completeness, we also used Kruskal-Wallis tests to conduct follow-up pairwise comparisons. We examined the interactions between the causal information type and behavioral advice using analyses of covariance (ANCOVAs). To examine what additional factors beyond experimental group were associated with internalized weight stigma [i.e. demographic and weight-related characteristics, and psychological variables (self-esteem, maladaptive eating attitudes, obesity causal beliefs)], we first conducted ANOVAs for continuous variables and $\chi^{2}$ tests for categorical variables. After the unadjusted analyses, we then conducted an ANCOVA with internalized weight stigma as the outcome variable, and demographic factors and all variables that had a $p$ value $<0.05$ in the unadjusted analyses included in the model as independent variables. Interest in personal and child's genetic test results for obesity was assessed using frequencies, and comparisons between the two were made using a paired-samples t test. We also examined whether people who said they were interested in getting genetic information for themselves were more likely than others to also be interested in getting genetic information for their children; this was done using Pearson's correlation and $\chi^{2}$ tests. $p$ values $<0.05$ were considered significant in all statistical analyses. All statistical analyses were performed using IBM SPSS Statistics 20 (Chicago, Ill., USA).

\section{Results}

\section{Demographic and Weight-Related Characteristics of Participants}

Of the 1,207 participants who completed the survey, 791 self-identified as being slightly or very overweight, and so were asked to complete the WBIS. Participants were excluded from the present analyses if they identified themselves as being slightly or very overweight but were calculated to have an objective BMI of less than 25 based on their self-reported height and weight: this led to the exclusion of 124 individuals. In addition, 12 participants were excluded because they had an unrealistically high calculated BMI of 55 or more. After these exclusions, the total number of participants for the present analyses was 655. Of these, 224 were randomly assigned to the genetic condition (112 received genetic information only, 112 received genetic information plus behavioral advice), 232 to the nongenetic (environment) condition (108 did not and 124 did receive additional behavioral advice), and 199 to the gene-environment condition (96 did not and 103 did receive behavioral advice) (fig. 1). 
Table 1. Demographic and weight-related characteristics of the 655 survey respondents who identified themselves as being overweight overall and by causal experimental group

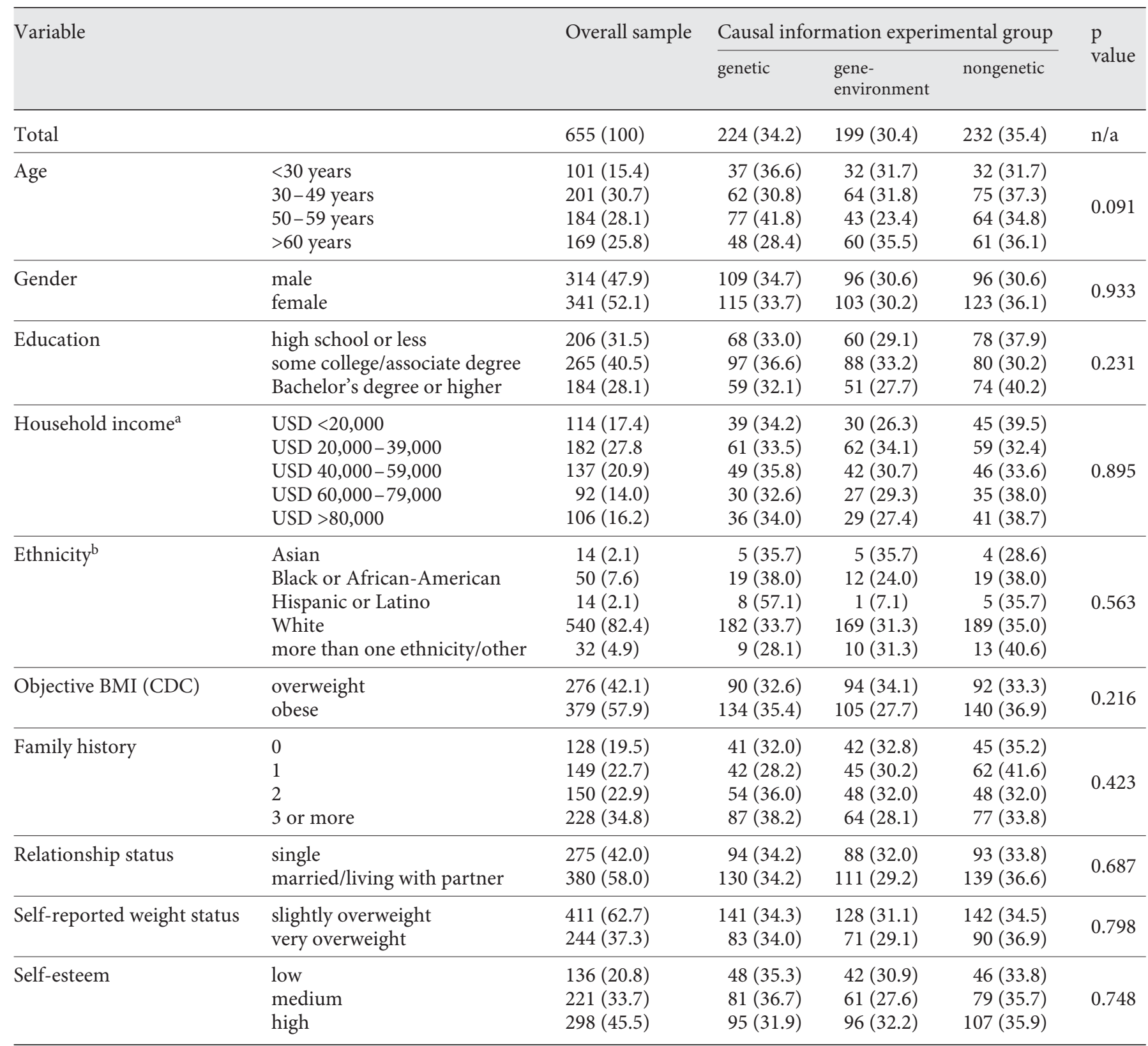

Values represent $\mathrm{n}(\%)$.

a 24 individuals responded 'don't know/unsure' of their household income. ${ }^{b} 5$ respondents declined to respond on their ethnicity.

As table 1 shows, the mean age of the eligible 655 participants was 48.5 years (range 18-86). Just over half (52.1\%) were female, and only $28.1 \%$ had a Bachelor's or higher degree; $45.2 \%$ had an annual household income of USD $<40,000$, and $82.4 \%$ were White. By definition, all participants included in the present analyses reported that they believed themselves to be overweight: $62.7 \%$ believed they were slightly overweight and $37.3 \%$ believed they were very overweight. When BMIs were calculated from self-reported height and weight and categorized ac- 
Fig. 2. Causal beliefs about obesity. Overall proportions of 655 overweight participants who agreed or strongly agreed that each of the 10 factors contribute to obesity.
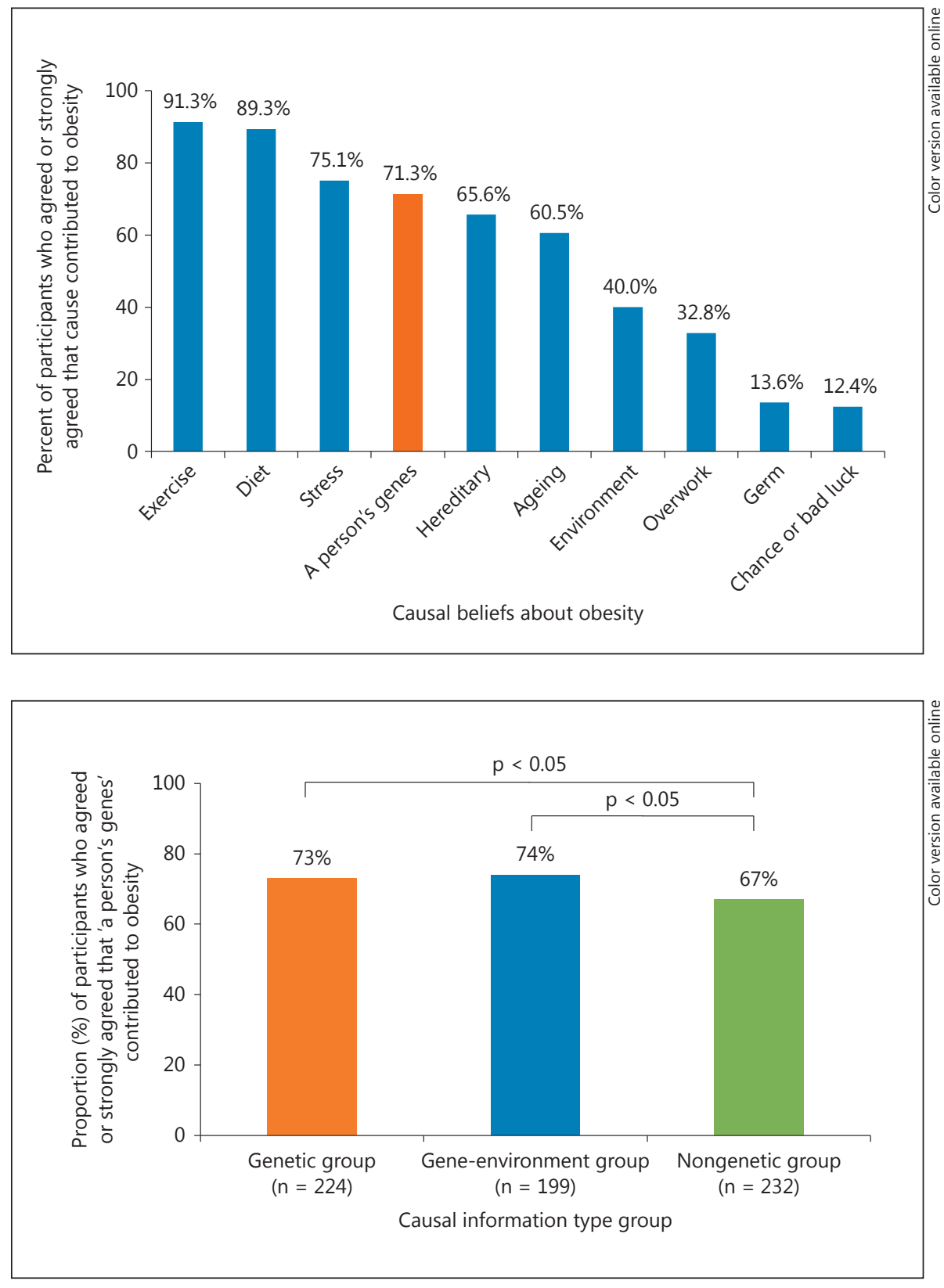

Fig. 3. Genetic causal beliefs compared between 655 overweight participants who received genetic, gene-environment, or nongenetic causal information about obesity. cording to CDC criteria, the mean BMI of the sample was $32.5(\mathrm{SD}=5.75$, range $25.0-54.9)$. Eighty percent of the participants reported that they had at least one overweight first-degree relative (parent, sibling, or child). The mean scores on the maladaptive eating attitudes subscales were $2.61(\mathrm{SD}=2.17)$ for restraint, $2.90(\mathrm{SD}=1.74)$ for weight concern, $2.86(\mathrm{SD}=1.69)$ for shape concern, and $2.15(\mathrm{SD}=1.84)$ for eating concern, indicating generally low levels of maladaptive eating attitudes. There were no differences on any of the demographic, weight-related, or maladaptive eating attitude subscales between the three main experimental causal information type groups (table 1).

\section{Impact of Genetic Information about Obesity on Causal Beliefs}

Figure 2 shows the overall proportions of participants who endorsed each of the 10 potential causes of obesity (i.e. 'agreed' or 'strongly agreed' that that factor was a cause of obesity). As shown in this figure, $71 \%$ of the par- 
Table 2. Internalized weight stigma and other weight-related cognitions among overweight individuals compared between participants who received different experimental types of obesity causal information and behavioral advice

\begin{tabular}{|c|c|c|c|c|c|c|c|c|c|c|c|}
\hline & \multicolumn{9}{|c|}{ Experimental groups } & \multirow{2}{*}{\multicolumn{2}{|c|}{$\begin{array}{l}\text { Causal information } \\
\times \text { behavioral advice } \\
\text { interaction sig. }\end{array}$}} \\
\hline & \multicolumn{5}{|c|}{ causal information type } & \multicolumn{4}{|c|}{ behavioral advice } & & \\
\hline & \multirow[t]{2}{*}{ genetic } & \multirow{2}{*}{$\begin{array}{l}\text { gene- } \\
\text { environment }\end{array}$} & \multirow[t]{2}{*}{ nongenetic } & \multicolumn{2}{|c|}{ main effect sig. } & \multirow[t]{2}{*}{ no } & \multirow[t]{2}{*}{ yes } & \multicolumn{2}{|c|}{ main effect sig. } & \multirow[t]{2}{*}{$\mathrm{F}$} & \multirow[t]{2}{*}{$\mathrm{p}$} \\
\hline & & & & K-W & $\mathrm{p}$ & & & $\mathrm{K}-\mathrm{W}$ & $\mathrm{p}$ & & \\
\hline Internalized weight stigma & $3.90 \pm 1.33$ & $3.66 \pm 1.37$ & $3.85 \pm 1.40$ & 4.16 & 0.13 & $3.83 \pm 0.72$ & $3.79 \pm 1.37$ & 0.33 & 0.57 & 1.06 & 0.35 \\
\hline Genetic causal belief & $3.88 \pm 0.93$ & $3.87 \pm 0.83$ & $3.71 \pm 0.88$ & 6.55 & 0.038 & $3.85 \pm 0.86$ & $3.78 \pm 0.90$ & 1.02 & 0.31 & 0.60 & 0.55 \\
\hline Diet causal belief & $4.31 \pm 0.84$ & $4.40 \pm 0.70$ & $4.35 \pm 0.71$ & 0.91 & 0.63 & $4.27 \pm 0.80$ & $4.43 \pm 0.70$ & 6.95 & 0.008 & 0.19 & 0.83 \\
\hline Exercise causal belief & $4.37 \pm 0.80$ & $4.41 \pm 0.64$ & $4.38 \pm 0.70$ & 0.14 & 0.93 & $4.35 \pm 0.73$ & $4.42 \pm 0.71$ & 1.28 & 0.26 & 0.51 & 0.60 \\
\hline Weight loss self-efficacy & $3.58 \pm 0.83$ & $3.57 \pm 0.88$ & $3.68 \pm 0.83$ & 2.03 & 0.36 & $3.59 \pm 0.81$ & $3.63 \pm 0.83$ & 0.28 & 0.60 & 0.84 & 0.43 \\
\hline Diet self-efficacy & $3.62 \pm 0.84$ & $3.56 \pm 0.87$ & $3.72 \pm 0.84$ & 2.74 & 0.25 & $3.54 \pm 0.85$ & $3.73 \pm 0.84$ & 8.10 & 0.004 & 0.05 & 0.95 \\
\hline Exercise self-efficacy & $3.52 \pm 0.86$ & $3.47 \pm 0.97$ & $3.63 \pm 0.85$ & 1.85 & 0.40 & $3.53 \pm 0.83$ & $3.55 \pm 0.96$ & 0.22 & 0.64 & 0.46 & 0.64 \\
\hline Diet response efficacy & $3.99 \pm 0.76$ & $4.04 \pm 0.68$ & $4.14 \pm 0.67$ & 5.36 & 0.068 & $4.00 \pm 0.70$ & $4.12 \pm 0.71$ & 3.28 & 0.070 & 0.56 & 0.57 \\
\hline Exercise response efficacy & $4.12 \pm 0.77$ & $4.11 \pm 0.68$ & $4.28 \pm 0.64$ & 6.30 & 0.043 & $4.13 \pm 0.73$ & $4.21 \pm 0.68$ & 1.19 & 0.28 & 0.20 & 0.82 \\
\hline Self-esteem & $3.24 \pm 1.11$ & $3.30 \pm 1.16$ & $3.30 \pm 1.09$ & 0.66 & 0.72 & $3.28 \pm 1.07$ & $3.27 \pm 1.17$ & 0.00 & 0.98 & 0.62 & 0.54 \\
\hline
\end{tabular}

The values represent means \pm SD. The main effect tests of significance were Kruskal-Wallis $(\mathrm{K}-\mathrm{W})$ tests. The interaction effects were calculated using ANOVAs. Bold highlights the variables that were significantly different between the groups. sig. = Significance.

ticipants agreed or strongly agreed that 'a person's genes' were a cause of obesity. The most endorsed cause was 'lack of exercise' (91\%) closely followed by 'diet or eating habits' (89\%), and the least endorsed cause was 'chance or bad luck' (12\%).

Specifically regarding genetic causal beliefs, 127 (19.4\%) of the sample overall strongly agreed, 340 (51.9\%) agreed, $144(22.0 \%)$ neither agreed nor disagreed, 27 (4.1\%) disagreed, and 17 (2.6\%) strongly disagreed that 'a person's genes' were a cause of obesity (mean score $=3.81$, $\mathrm{SD}=0.88$, range $=1-5)$. For diet causal beliefs, these proportions were $319(48.7 \%), 266(40.6 \%), 56(8.5 \%), 10$ $(1.5 \%)$, and $4(0.6 \%)$, respectively (mean score $=4.35$, $\mathrm{SD}=0.752$, range $=1-5)$. For exercise causal beliefs, these proportions were 325 (49.6\%), 273 (41.7\%), 47 (7.2\%), 5 $(0.8 \%)$, and $5(0.8 \%)$ (mean score $=4.39, \mathrm{SD}=0.720$, range $=1-5)$.

As table 2 shows, there was a significant difference between causal information conditions on genetic causal belief $(H(2)=6.55, \mathrm{p}=0.038)$. When we conducted post hoc pairwise comparisons to explore the relationships further, we found that, as predicted, genetic causal belief was higher in the genetic condition than in the nongenetic condition ( 3.88 vs. $3.71, H(1)=5.55, \mathrm{p}=0.018$ ), higher in the gene-environment than in the nongenetic condition ( 3.87 vs. $3.71, H(1)=3.89, \mathrm{p}=0.049$ ), and did not differ between the gene-environment and genetic conditions ( 3.87 vs. $3.88, H(1)=0.18, \mathrm{p}=0.67$ ) (see fig. 3 for proportions of participants who agreed or strongly agreed that genes influence obesity risk by causal information type group). There was no difference between the behavioral advice conditions, and no causal information $\times$ behavioral advice interaction was observed (table 2 ).

Table 2 also shows the mean scores for diet and exercise causal beliefs compared between the experimental groups. There was a significant difference in diet causal beliefs between the behavioral advice conditions $(H(1)=$ $6.95, \mathrm{p}=0.008$ ), with individuals who received the behavioral advice being more likely to hold diet causal beliefs than individuals who did not receive the behavioral advice, but there was no difference according to causal information type $(H(2)=0.91, \mathrm{p}=0.63)$ and no causal information $\times$ behavioral advice interaction. For exercise causal beliefs, there were no significant difference by causal group or behavioral advice as well as no interactions.

\section{Impact of Genetic Information about Obesity on Internalized Weight Stigma}

The mean (SD) internalized weight stigma score was 3.81 (1.37). This is similar to the mean (SD) of 3.95 (1.28) published in the original WBIS development study [16]. Internalized weight stigma did not differ significantly between causal information type groups (table 3 ). In post hoc pairwise comparisons, there were no differences in internalized weight stigma between the genetic and nongenetic conditions, the gene-environment and genetic conditions, or the gene-environment and nongenetic 
Table 3. Associations between internalized weight stigma (WBIS) and independent variables among 655 online survey respondents who self-reported as being overweight

\begin{tabular}{|c|c|c|c|c|c|c|}
\hline \multicolumn{3}{|l|}{ Variable } & \multirow{2}{*}{$\begin{array}{l}\mathrm{n} \\
655\end{array}$} & \multirow{2}{*}{$\begin{array}{l}\begin{array}{l}\text { WBIS, } \\
\text { mean } \pm \text { SD }\end{array} \\
3.81 \pm 1.37\end{array}$} & \multirow{2}{*}{$\begin{array}{l}\text { Unadjusted sig. } \\
\text { p value } \\
\text { n/a }\end{array}$} & \multirow{2}{*}{$\begin{array}{l}\begin{array}{l}\text { Adjusted sig. } \\
\text { p value }\end{array} \\
\text { n/a }\end{array}$} \\
\hline Total & & & & & & \\
\hline $\begin{array}{l}\text { Causal experimental } \\
\text { group }\end{array}$ & $\begin{array}{l}\text { genetic } \\
\text { nongenetic } \\
\text { gene-environment }\end{array}$ & & $\begin{array}{l}224 \\
232 \\
199\end{array}$ & $\begin{array}{l}3.90 \pm 1.33 \\
3.85 \pm 1.40 \\
3.66 \pm 1.37\end{array}$ & 0.15 & 0.089 \\
\hline Age & $\begin{array}{l}<30 \text { years } \\
30-49 \text { years } \\
50-59 \text { years } \\
>60 \text { years }\end{array}$ & & $\begin{array}{l}101 \\
201 \\
184 \\
169\end{array}$ & $\begin{array}{l}4.38 \pm 1.16 \\
4.09 \pm 1.34 \\
3.63 \pm 1.40 \\
3.34 \pm 1.30\end{array}$ & $<0.001$ & $<0.001$ \\
\hline Household income $^{a}$ & $\begin{array}{l}\text { USD }<20,000 \\
\text { USD } 20,000-39,000 \\
\text { USD } 40,000-59,000 \\
\text { USD } 60,000-79,000 \\
\text { USD }>80,000\end{array}$ & & $\begin{array}{r}114 \\
182 \\
137 \\
92 \\
106\end{array}$ & $\begin{array}{l}3.99 \pm 1.38 \\
3.82 \pm 1.39 \\
3.79 \pm 1.39 \\
3.81 \pm 1.40 \\
3.67 \pm 1.27\end{array}$ & 0.55 & - \\
\hline Ethnicity $^{\mathrm{b}}$ & $\begin{array}{l}\text { Asian } \\
\text { Black or African-American } \\
\text { Hispanic or Latino } \\
\text { White } \\
\text { more than one ethnicity/other }\end{array}$ & & $\begin{array}{r}14 \\
50 \\
14 \\
540 \\
32\end{array}$ & $\begin{array}{l}4.30 \pm 0.99 \\
3.49 \pm 1.43 \\
4.19 \pm 1.02 \\
3.82 \pm 1.38 \\
3.70 \pm 1.33\end{array}$ & 0.21 & - \\
\hline $\begin{array}{l}\text { Relationship } \\
\text { status }\end{array}$ & $\begin{array}{l}\text { single } \\
\text { married/living with partner }\end{array}$ & & $\begin{array}{l}275 \\
380\end{array}$ & $\begin{array}{l}3.93 \pm 1.40 \\
3.72 \pm 1.34\end{array}$ & 0.056 & - \\
\hline $\begin{array}{l}\text { Self-reported } \\
\text { weight status }\end{array}$ & $\begin{array}{l}\text { slightly overweight } \\
\text { very overweight }\end{array}$ & & $\begin{array}{l}411 \\
244\end{array}$ & $\begin{array}{l}3.44 \pm 1.26 \\
4.44 \pm 1.33\end{array}$ & $<0.001$ & $<0.001$ \\
\hline Self esteem & $\begin{array}{l}\text { low } \\
\text { medium } \\
\text { high }\end{array}$ & & $\begin{array}{l}136 \\
221 \\
298\end{array}$ & $\begin{array}{l}5.03 \pm 1.16 \\
3.97 \pm 1.09 \\
3.13 \pm 1.21\end{array}$ & $<0.001$ & $<0.001$ \\
\hline $\begin{array}{l}\text { Evaluation of the } \\
\text { information }\end{array}$ & 'easy to read' & $\begin{array}{l}\text { no } \\
\text { yes }\end{array}$ & $\begin{array}{l}113 \\
542\end{array}$ & $\begin{array}{l}3.81 \pm 1.13 \\
3.81 \pm 1.42\end{array}$ & 0.99 & - \\
\hline & 'relevant to me' & $\begin{array}{l}\text { no } \\
\text { yes }\end{array}$ & $\begin{array}{l}206 \\
449\end{array}$ & $\begin{array}{l}3.32 \pm 1.22 \\
4.04 \pm 1.38\end{array}$ & $<0.001$ & 0.041 \\
\hline & 'useful to me' & $\begin{array}{l}\text { no } \\
\text { yes }\end{array}$ & $\begin{array}{l}247 \\
408\end{array}$ & $\begin{array}{l}3.54 \pm 1.29 \\
3.98 \pm 1.39\end{array}$ & $<0.001$ & 0.68 \\
\hline & 'provided me with new information' & $\begin{array}{l}\text { no } \\
\text { yes }\end{array}$ & $\begin{array}{l}349 \\
306\end{array}$ & $\begin{array}{l}3.72 \pm 1.32 \\
3.92 \pm 1.41\end{array}$ & 0.057 & - \\
\hline
\end{tabular}


Table 3 (continued)

\begin{tabular}{|c|c|c|c|c|c|c|}
\hline Variable & & & $\mathrm{n}$ & $\begin{array}{l}\text { WBIS, } \\
\text { mean } \pm \text { SD }\end{array}$ & $\begin{array}{l}\text { Unadjusted sig. } \\
\text { p value }\end{array}$ & $\begin{array}{l}\text { Adjusted sig. } \\
\text { p value }\end{array}$ \\
\hline \multirow[t]{3}{*}{$\begin{array}{l}\text { Maladaptive } \\
\text { eating attitudes }\end{array}$} & shape concern & $\begin{array}{l}\text { low } \\
\text { high }\end{array}$ & $\begin{array}{r}48 \\
607\end{array}$ & $\begin{array}{l}3.02 \pm 1.14 \\
3.87 \pm 1.37\end{array}$ & $<0.001$ & 0.24 \\
\hline & weight concern & $\begin{array}{l}\text { low } \\
\text { high }\end{array}$ & $\begin{array}{r}44 \\
611\end{array}$ & $\begin{array}{l}2.91 \pm 1.18 \\
3.88 \pm 1.37\end{array}$ & $<0.001$ & 0.46 \\
\hline & eating concern & $\begin{array}{l}\text { low } \\
\text { high }\end{array}$ & $\begin{array}{l}146 \\
506\end{array}$ & $\begin{array}{l}2.82 \pm 1.09 \\
4.10 \pm 1.31\end{array}$ & $<0.001$ & $<0.001$ \\
\hline \multirow[t]{5}{*}{$\begin{array}{l}\text { Causal beliefs } \\
\text { about obesity }\end{array}$} & 'Diet or eating habits' & $\begin{array}{l}\text { no } \\
\text { yes }\end{array}$ & $\begin{array}{r}70 \\
585\end{array}$ & $\begin{array}{l}3.77 \pm 1.32 \\
3.81 \pm 1.39\end{array}$ & 0.81 & - \\
\hline & 'Overwork' & $\begin{array}{l}\text { no } \\
\text { yes }\end{array}$ & $\begin{array}{l}440 \\
215\end{array}$ & $\begin{array}{l}3.74 \pm 1.38 \\
3.95 \pm 1.33\end{array}$ & 0.61 & - \\
\hline & 'A person's genes' & $\begin{array}{l}\text { no } \\
\text { yes }\end{array}$ & $\begin{array}{l}188 \\
467\end{array}$ & $\begin{array}{l}3.81 \pm 1.35 \\
3.81 \pm 1.38\end{array}$ & 0.98 & - \\
\hline & 'Hereditary - it runs in families' & $\begin{array}{l}\text { no } \\
\text { yes }\end{array}$ & $\begin{array}{l}225 \\
430\end{array}$ & $\begin{array}{l}3.73 \pm 1.37 \\
3.85 \pm 1.37\end{array}$ & 0.29 & - \\
\hline & 'The environment' & $\begin{array}{l}\text { no } \\
\text { yes }\end{array}$ & $\begin{array}{l}393 \\
262\end{array}$ & $\begin{array}{l}3.76 \pm 1.35 \\
3.89 \pm 1.39\end{array}$ & 0.25 & - \\
\hline
\end{tabular}

sig. = Significance.

a 24 individuals responded 'don't know/unsure' of their household income. ${ }^{b} 5$ respondents declined to respond on their ethnicity.

conditions (fig. 4). Thus, the hypothesis that genetic information would be associated with lower internalized weight stigma compared to nongenetic information was not supported. There was also no significant difference in internalized weight stigma by behavioral advice, and no causal information $\times$ behavioral advice interaction for this or any of the other outcome variables was found. Since we had $90 \%$ power to detect a small effect size of 0.3 and the group differences that we actually found were smaller than this (effect sizes of less than 0.2), the nonsig- nificant differences are unlikely to be attributable to a lack of statistical power.

\section{Impact of Genetic Information about Obesity on \\ Perceived Control}

The mean (SD) for perceived control over weight loss was 3.61 (0.85), for perceived control over diet it was 3.64 (0.85), and for perceived control over exercise it was 3.54 $(0.89)$. There were no significant differences or interactions in post hoc paired analyses in perceived control over 
Fig. 4. Internalized weight stigma compared between 655 overweight participants who received genetic, gene-environment, or nongenetic causal information about obesity.

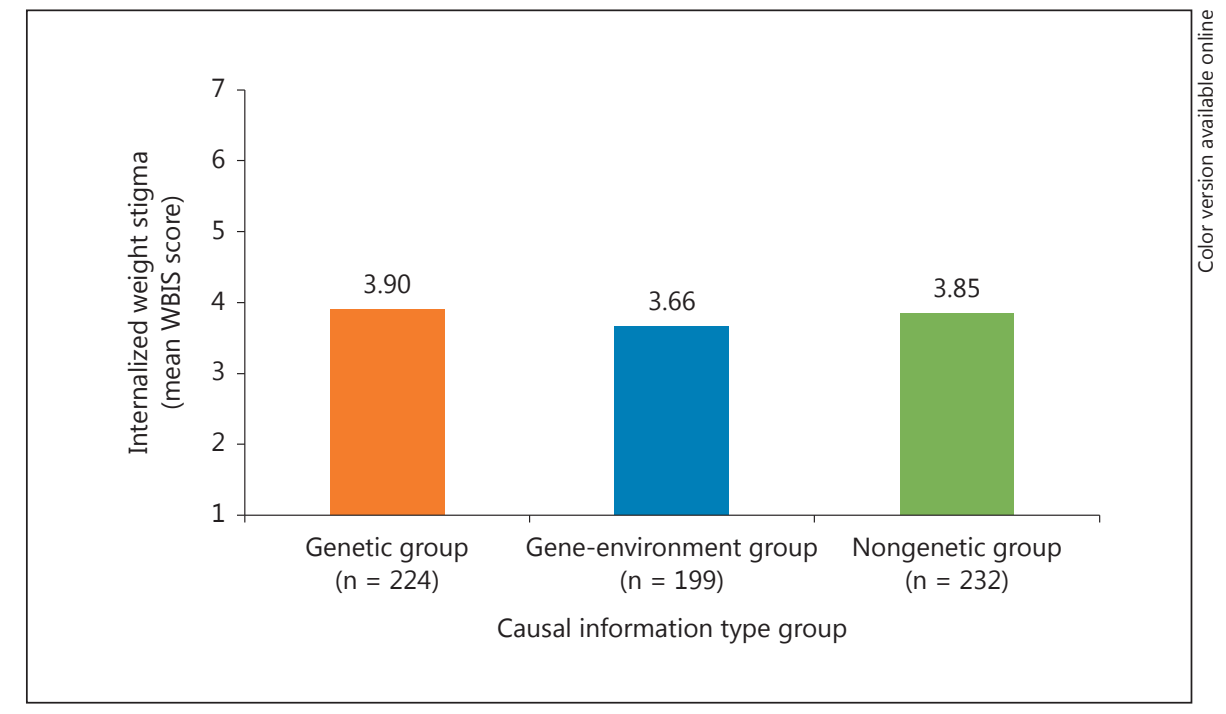

weight loss or exercise (table 2). In post hoc paired analyses, there was however a significant difference between behavioral advice groups in perceived control over diet, with people who received behavioral advice reporting greater perceived control over diet than participants who did not receive behavioral advice (3.54 vs. $3.73, H(1)=$ $8.10, \mathrm{p}=0.004)$. There was no significant difference by causal information type and no causal information $\times$ behavioral advice interaction for perceived control over diet.

\section{Impact of Genetic Information about Obesity on}

Perceived Response Efficacy

The mean (SD) for confidence that physical activity can reduce a person's weight ('physical activity response efficacy') was 4.17 (0.70). A significant difference between the three causal information groups was detected for physical activity response efficacy $(H(2)=6.30, \mathrm{p}=0.043)$, although in subsequent post hoc paired analyses, the significant difference was between the gene-environment information and nongenetic information groups (4.11 vs. $4.28, H(1)=5.70, \mathrm{p}=0.0 .017$ ), while the genetic and nongenetic information groups did not differ significantly (4.12 vs. $4.28, H(1)=3.49, \mathrm{p}=0.062$ ).

The mean (SD) for confidence that eating a healthy diet can reduce a person's weight ('diet response efficacy') was 4.06 (0.71). Diet response efficacy did not differ between the experimental groups, and there were no other significant differences or interactions by causal information or behavioral advice on either of the perceived response efficacy outcomes (table 2).

\section{Impact of Genetic Information about Obesity on} Self-Esteem

The mean self-esteem score in the sample overall was $3.28(\mathrm{SD}=1.12$, range $=1-5)$. Using the continuous variable for self-esteem and ANOVA, there were no significant differences or interactions between the experimental groups in self-esteem. Response options were also re-categorized into low (i.e. response score of 1 or 2), medium (response score of 3 ), and high (response score of 4 or 5 ). Using this categorization, $136(20.8 \%)$ respondents had low self-esteem, 221 (33.7\%) had medium self-esteem, and 298 (45.5\%) had high self-esteem. There were also no significant differences between the experimental conditions when we conducted a series of $\chi^{2}$ tests using the categorized self-esteem variable.

\section{Factors Associated with Internalized Weight Stigma}

When exploring what factors were associated with internalized weight bias, we found that, in the adjusted model, internalized weight stigma was associated with: younger age, higher self-reported weight status, believing that ageing, stress, and worry contribute to obesity, higher eating concern (EDE-Q subscale), lower self-esteem, and perceiving the experimental information to be personally relevant (table 3 ).

\section{Interest in Personalized Genetic Information about Obesity}

When asked whether they would be interested in receiving personalized genetic information about obesity risk, 420 (64\%) of the participants responded 'yes prob- 
Table 4. Proportions of 655 self-reported overweight online survey respondents who were interested in receiving personalized genetic information about obesity risk for themselves and/or their children

\begin{tabular}{lrrr}
\hline & \multicolumn{2}{c}{ Genetic information for child } & \multirow{2}{*}{ Total } \\
\cline { 2 - 3 } & not interested & interested & \\
\hline Genetic information for self & & \\
$\quad$ Not interested & $179(76.2)$ & $56(23.8)$ & $235(100)$ \\
$\quad$ Interested & $43(10.2)$ & $377(89.8)$ & $420(100)$ \\
Total & $222(33.9)$ & $433(66.1)$ & $655(100)$ \\
\hline
\end{tabular}

Values represent $\mathrm{n}(\%)$.

ably' or 'yes definitely' regarding finding out about their own risk of obesity, and 433 (66\%) responded 'yes probably' or 'yes definitely' regarding finding out about their child's risk of obesity. A paired-samples t test indicated that these two proportions were not significantly different from one another $(\mathrm{t}=-1.31$, d.f. $=654, \mathrm{p}=0.19)$. There was a strong correlation between interest in genetic information for oneself and interest in receiving genetic information for one's child $(\mathrm{R}=0.70, \mathrm{p}<0.001)$; similarly, when re-categorized into dichotomized outcomes, people who stated that they were 'definitely' or 'probably' interested in getting genetic information for themselves were significantly more likely than those who were disinterested to say that they were also interested in getting genetic information for their children $\left(\chi^{2}(1)=\right.$ 292.4, p < 0.001) (table 4).

\section{Discussion}

Our main goal in this study was to examine the cognitive outcomes of providing overweight and obese individuals with some information about the role of genetics in obesity. We hypothesized that providing overweight people with genetic information could have a positive outcome in that it could be associated with lower internalized weight stigma as well as perhaps higher self-esteem, but also that there could conversely be negative outcomes such as lower confidence in their ability to control their weight or change their behavior. We also hypothesized that genetic information about obesity presented alone could be associated with adverse outcomes such as diminished perceptions of control, but that if accompanied by information emphasizing that even genetic risk can be reduced by lifestyle changes then these potentially adverse outcomes could be diminished. These hypotheses hinged on attribution theory which posits that people's beliefs about the causes of a condition are central to their beliefs about what they might be able to do to prevent or treat that condition.

Our primary hypothesis regarding internalized weight stigma was not supported: there was no difference in internalized weight stigma between participants regardless of whether they received the genetic, gene-environment, or nongenetic information about the causes of obesity. These results from our study, which is the first study to examine the associations between providing overweight people with genetic information and internalized weight stigma, tentatively suggest that disseminating knowledge about the genetic causes of obesity may have neither a harmful nor a beneficial effect on internalized weight stigma. However, this was a single, brief, written educational intervention, and it is possible that this is not enough to significantly impact something so entrenched as overweight persons' negative feelings about themselves based on their weight, even in the short term. It is not clear whether multiple exposures to information about obesity genetics over time or more intensive interventions in terms of both time and content would have a different impact on internalized weight stigma. It would be interesting to explore the effects of providing the information in a way that did not rely on reading written text and with images or even animations (see, for example, our animated video about whole-genome sequencing: http://www.youtube. $\mathrm{com} /$ watch? $\mathrm{v}=\mathrm{IXamRS85hXU} \& \mathrm{hd}=1$ ). Presenting the information in such a way could maybe increase the extent to which it is processed and attended to, and therefore the significance of its impact.

In addition, we deliberately presented the genetic information without giving it any 'emotional loading', e.g. we did not state explicitly that genetic information had implications for willpower. A recent study examining how people in online weight loss communities discuss obesity and genetics found that people often use language like 'fighting genes', i.e. that they are having to battle their genes in their efforts to maintain or engage in weight loss efforts [54]. Perhaps linking the genetic causal information more explicitly to messages that have implications for self-image and weight management techniques might have a greater impact on overweight individuals' internalized weight stigma. For example, one such message might state that some people's genetics mean that for them it genuinely is more of a struggle to maintain a healthy weight than it is for some other people, and that for those genetically susceptible people it really is more of 
a battle, but that this just means it is even more important for them to engage in healthy practices such as keeping high-fat foods out of the kitchen at home (e.g. [55]).

It is also possible, of course, that shifting people's beliefs about the causes of obesity to incorporate more of a genetic component simply will not have a significant impact on internalized weight stigma. Only one study has attempted to reduce and has successfully reduced internalized weight stigma using a different measure of internalized weight bias, the weight self-stigma questionnaire [38], and that was an intensive intervention in which participants completed a 1-day workshop which emphasized acceptance and mindfulness and was designed to reduce weight stigma $[37,38]$. The authors speculated that the intervention helped reduce experiential avoidance (the tendency to avoid, suppress, or change unwanted thoughts and feelings, even when doing so produces harm) related to weight self-stigma, and that the intervention created the psychological flexibility needed to accept the uncomfortable thoughts $[37,38]$. They also argued that it is perhaps only when one can acknowledge the uncomfortable emotions that one can make healthy behavioral changes related to weight control $[37,38]$. It is possible that focusing on self-esteem and body image acceptance rather than genetic messages may be more effective to reduce internalized weight stigma [56], although clearly a 1-day workshop is not a practicable solution on a wide public health level.

We found that younger age, higher self-reported weight status, and lower self-esteem were all associated with higher internalized weight stigma. Previous studies have found similar positive associations between internalized weight stigma and low self-esteem [16], but they found no association with age $[16,38]$ and did not examine the association between internalized weight stigma and self-reported or observed weight status $[16,38]$. We also found that higher eating concern was associated with higher internalized weight stigma. Other studies have also found associations between weight stigma and maladaptive eating attitudes and behavior $[16,18,19]$. The associations with lower self-esteem, maladaptive eating attitudes, and higher self-reported weight status point to the emotional and psychological complexity of internalized weight stigma. As mentioned above, perhaps an animation incorporating messages about both obesity genomics and positive self-esteem and body image acceptance would be one accessible way to address this highly complex self-stigma construct in a format that could be widely disseminated.

We found that the experimental manipulation was successful in that genetic causal beliefs were higher in the genetic and gene-environment conditions than in the nongenetic experimental condition. Thus, it appears that the experimental information provided to participants accurately communicated the desired content. Critically, diet and exercise causal beliefs did not differ significantly between the experimental groups. Over $85 \%$ of the participants, regardless of the experimental group, agreed that diet and exercise contribute to the development of obesity. This is important because there have been previous concerns that providing genetic information to individuals may reduce people's focus on the importance of diet and exercise. Our overweight participants still felt that improving nutrition and physical activity were important behavioral modifications needed for weight loss even in the presence of genetic information. Although previous surveys have examined cross-sectional relationships between genetic and lifestyle causal beliefs about obesity [35, 57-61], the present study is the first to directly examine how causal beliefs differ between individuals provided with genetic versus nongenetic information. Our results importantly suggest that increasing people's genetic causal beliefs about obesity does not have the 'knock-on' effect of reducing their lifestyle causal beliefs.

We found very few differences between the genetic, nongenetic, and gene-environment groups in perceptions of control, efficacy, or self-esteem. There was some suggestion that participants who read the genetic information had lower confidence than participants who read the nongenetic information that being more physically active could help weight loss, which potentially supports concerns that informing people that a trait is genetic reduces their belief that they can control that trait with behavioral changes [62]. However, this would need to be replicated in more studies given the multiple tests conducted and the small between-group differences in absolute terms.

Finally, our finding that two thirds of these overweight individuals were interested in receiving personalized genetic information about their own and their children's obesity risk adds to the few previous studies that have found high levels of interest in genetic testing for obesity among clinical populations [63, 64], albeit at lower levels than for other diseases such as heart disease, type 2 diabetes, and cancer [65]. We speculate that perhaps the high level of interest in genetic testing for obesity risk observed in the present study is due to overweight people believing that if they obtain a 'high-risk' result from genetic testing for obesity risk, this could explain their struggles with weight. This is supported to some extent by the handful of studies to date that have addressed this issue in other 
populations. In one focus group study, obese adults reported strong interest in personal genetic testing for obesity risk [63] and in another focus group study with parents of overweight children, the primary reason for interest in having their children tested for genetic risk of obesity was the perceived helpfulness of the result in framing behavior of both parent and child in preventing development of obesity [64]. In a UK study, a panel sample of individuals with weight concerns (mean BMI $=35$ ) expressed greater interest in genetic testing for obesity risk than a student sample (mean BMI $=23$ ). Both samples believed a higher-risk result would increase their motivation to change their behavior more than an averagerisk result, and the panel sample also believed they would feel relief about having an explanation for their body weight [66]. Another UK study using hypothetical scenarios or 'vignettes' similarly found that individuals reported greater intention to eat healthily in response to a high-risk result from a genetic test for obesity compared with no risk information [67].

Limitations of the present study included that the respondents were primarily White, that we did not use a pre-test/post-test design, and that we did not include a no-information control group. In addition, the causal experimental conditions could all be considered 'uncontrollable' aspects of obesity. When we designed the experiment, we wanted to include the opposite of a genetic causal experimental group, and hence we had our nongenetic experimental group focus on the obesogenic environment. However, environmental causal information could be considered an external uncontrollable aspect of obesity. It is possible that by comparing two uncontrollable causes of obesity we reduced the likelihood of finding significant between-group differences. A no-information control group would have helped clarify this. That said, we did provide behavioral advice (i.e. a 'controllable' aspect of obesity) to half of our participants and found that internalized weight stigma did not differ depending on the presence or absence of this information. The wording of some of the response efficacy items (e.g. 'If I eat a healthy diet, I am less likely to become obese') could have been confusing or viewed as inapplicable by respondents who already were obese.

These limitations need to be weighed against the study strengths. To our knowledge, this is the first study that has attempted to reduce internalized weight stigma in the general population. In addition, our sample size was relatively large and the demographic characteristics of our sample were representative of the general US population. For example, in terms of education, $28 \%$ of our sample had completed a Bachelor's degree or higher, which is similar to the $27 \%$ of the adult population in the 2010 census [68]. The proportion of individuals who had completed high school or less was lower in our sample than in the general population ( 32 vs. $45 \%$, respectively), and figures were similar for income: $45 \%$ (our sample) and $42 \%$ (2010 census) had an annual household income of USD $<40,000$ per year [68].

In conclusion, generic genetic information about obesity was not associated with significant differences compared to nongenetic information regarding how overweight individuals thought and felt about themselves in this study, suggesting that at least brief information about obesity genetics will have neither a positive nor a negative impact on overweight people. However, over two thirds of this nonclinical population were interested in receiving personalized genetic information about their obesity risk, despite believing that they were already overweight. The potential benefits and possible harms of providing overweight people with general and personalized genetic information about obesity warrant further empirical investigation. More research is needed to evaluate the effect of genetic information on how individuals perceive themselves and on their confidence in their ability to change behavior.

\section{Acknowledgments}

We gratefully acknowledge Dr. Rebecca Puhl and Dr. Tom Hildebrandt for their contributions to the study design, and Dr. Ellen van Jaarsfeld for her valuable statistical advice on this paper.
References

Informing Overweight Individuals about the Role of Genetics in Obesity
Hum Hered 2013;75:186-203 DOI: $10.1159 / 000353712$
4 Hatzenbuehler ML, Phelan JC, Link BG: Stigma as a fundamental cause of population health inequalities. Am J Public Health 2013; 103:813-821. (author reply). JAMA 2010;303:1695-1696.

2 Puhl RM, Heuer CA: The stigma of obesity: a review and update. Obesity (Silver Spring) 2009;17:941-964.

3 Link BG, Phelan JC: Stigma and its public health implications. Lancet 2006;367:528529.
Link BG, Struening EL, Neese-Todd S, Asmussen S, Phelan JC: Stigma as a barrier to recovery: the consequences of stigma for the self-esteem of people with mental illnesses. Psychiatr Serv 2001;52:1621-1626. 
6 Ritsher JB, Phelan JC: Internalized stigma 21 Hebebrand J, Volckmar AL, Knoll N, Hinney predicts erosion of morale among psychiatric outpatients. Psychiatry Res 2004;129:257265.

7 Livingston JD, Boyd JE: Correlates and consequences of internalized stigma for people living with mental illness: a systematic review and meta-analysis. Soc Sci Med 2010;71: 2150-2161.

8 Gudzune KA, Beach MC, Roter DL, Cooper LA: Physicians build less rapport with obese patients. Obesity (Silver Spring) 2013, E-pub ahead of print.

$\checkmark$ Drury CA, Louis M: Exploring the association between body weight, stigma of obesity, and health care avoidance. J Am Acad Nurse Pract 2002;14:554-561.

10 Friedman KE, Reichmann SK, Costanzo PR, Zelli A, Ashmore JA, Musante GJ: Weight stigmatization and ideological beliefs: relation to psychological functioning in obese adults. Obes Res 2005;13:907-916.

11 Myers A, Rosen JC: Obesity stigmatization and coping: relation to mental health symptoms, body image, and self-esteem. Int J Obes Relat Metab Disord 1999;23:221-230.

12 Puhl RM, Brownell KD: Confronting and coping with weight stigma: an investigation of overweight and obese adults. Obesity (Silver Spring) 2006;14:1802-1815.

13 Vartanian LR, Shaprow JG: Effects of weight stigma on exercise motivation and behavior: a preliminary investigation among collegeaged females. J Health Psychol 2008;13:131138.

14 Wang SS, Brownell KD, Wadden TA: The influence of the stigma of obesity on overweight individuals. Int J Obes Relat Metab Disord 2004;28:1333-1337.

-15 Schwartz MB, Vartanian LR, Nosek BA, Brownell KD: The influence of one's own body weight on implicit and explicit anti-fat bias. Obesity (Silver Spring) 2006;14:440447.

16 Durso LE, Latner JD: Understanding self-directed stigma: development of the weight bias internalization scale. Obesity (Silver Spring) 2008;16(suppl 2):S80-S86.

17 Davison KK, Birch LL: Predictors of fat stereotypes among 9-year-old girls and their parents. Obes Res 2004;12:86-94.

18 Davison KK, Schmalz DL, Young LM, Birch LL: Overweight girls who internalize fat stereotypes report low psychosocial well-being. Obesity (Silver Spring) 2008;16(suppl 2):S30S38.

19 Puhl RM, Moss-Racusin CA, Schwartz MB: Internalization of weight bias: implications for binge eating and emotional well-being. Obesity (Silver Spring) 2007;15:19-23.

20 Vartanian LR, Novak SA: Internalized societal attitudes moderate the impact of weight stigma on avoidance of exercise. Obesity 2011;19:757-762.
A: Chipping away the 'missing heritability' GIANT steps forward in the molecular elucidation of obesity - but still lots to go. Obes Facts 2010;3:294-303.

22 Crandall CS: Prejudice against fat people: ideology and self-interest. J Pers Soc Psychol 1994;66:882-894.

23 Phelan JC: Geneticization of deviant behavior and consequences for stigma: the case of mental illness. J Health Soc Behav 2005;46:307322.

24 Pescosolido BA, Martin JK, Long JS, Medina TR, Phelan JC, Link BG: 'A disease like any other'? A decade of change in public reactions to schizophrenia, depression, and alcohol dependence. Am J Psychiatry 2010;167:13211330.

25 Rüsch N, Todd AR, Bodenhausen GV, Corrigan PW: Biogenetic models of psychopathology, implicit guilt, and mental illness stigma. Psychiatry Res 2010;179:328-332.

26 Hilbert A, Rief E, Braehler E: Stigmatizing attitudes toward obesity in a representative population-based sample. Obesity 2008; 16 : 1529-1534.

27 Lippa NC, Sanderson SC: Impact of information about obesity genomics on the stigmatization of overweight individuals: an experimental study. Obesity (Silver Spring) 2012;20: 2367-2376.

28 Teachman BA, Gapinski KD, Brownell KD, Rawlins M, Jeyaram S: Demonstrations of implicit anti-fat bias: the impact of providing causal information and evoking empathy. Health Psychol 2003;22:68-78.

29 Puhl RM, Schwartz MB, Brownell KD: Impact of perceived consensus on stereotypes about obese people: a new approach for reducing bias. Health Psychol 2005;24:517-525.

30 Bannon KL, Hunter-Reel D, Wilson GT; Karlin RA: The effects of causal beliefs and binge eating on the stigmatization of obesity. Int J Eat Disord 2009;42:118-124.

31 O’Brien KS, Puhl RM, Latner JD, Mir AS, Hunter JA: Reducing anti-fat prejudice in preservice health students: a randomized trial. Obesity 2010;18:2138-2144.

32 Persky S, Eccleston CP: Impact of genetic causal information on medical students' clinical encounters with an obese virtual patient: health promotion and social stigma. Ann Behav Med 2011;41:363-372.

33 Conradt M, Dierk JM, Schlumberger P, Albohn C, Rauh E, Hinney A, Hebebrand J, Rief $\mathrm{W}$ : A consultation with genetic information about obesity decreases self-blame about eating and leads to realistic weight loss goals in obese individuals. J Psychosom Res 2009;66: 287-295.

34 Rief W, Conradt M, Dierk JM, Rauh E, Schlumberger P, Hinney A, Hebebrand J: Is information on genetic determinants of obesity helpful or harmful for obese people? - A randomized clinical trial. J Gen Intern Med 2007;22:1553-1559.
35 Hilbert A, Dierk JM, Conradt M, Schlumberger P, Hinney A, Hebebrand J, Rief W: Causal attributions of obese men and women in genetic testing: implications of genetic/biological attributions. Psychol Health 2009;24: 749-761.

36 Geller G, Bernhardt BA, Holtzman NA: The media and public reaction to genetic research. JAMA 2002;287:773.

37 Lillis J, Hayes SC, Bunting K, Masuda A: Teaching acceptance and mindfulness to improve the lives of the obese: a preliminary test of a theoretical model. Ann Behav Med 2009;37:58-69.

38 Lillis, J, Luoma JB, Levin ME, Hayes SC: Measuring weight self-stigma: the weight self-stigma questionnaire. Obesity (Silver Spring) 2010;18:971-976.

-39 Hebebrand J, Hinney A: Environmental and genetic risk factors in obesity. Child Adolesc Psychiatr Clin N Am 2009;18:83-94.

40 Bacon JG, Scheltema KE, Robinson BE: Fat phobia scale revisited: the short form. Int $\mathrm{J}$ Obes Relat Metab Disord 2001;25:252-257.

41 Brownell KD: The humbling experience of treating obesity: should we persist or desist? Behav Res Ther 2010;48:717-719.

42 Brownell KD, Kersh R, Ludwig DS, Post RC, Puhl RM, Schwartz MB, Willett WC: Personal responsibility and obesity: a constructive approach to a controversial issue. Health Aff (Millwood) 2010;29:379-387.

43 Stunkard AJ, Sørensen TI, Hanis C, Teasdale TW, Chakraborty R, Schull WJ, Schulsinger F: An adoption study of human obesity. N Engl J Med 1986;314:193-198.

44 Frayling TM, Timpson NJ, Weedon MN, et al: A common variant in the FTO gene is associated with body mass index and predisposes to childhood and adult obesity. Science 2007; 316:889-894.

45 Centers for Disease Control and Prevention: Defining overweight and obesity. 2010. http:// www.cdc.gov/obesity/defining.html.

46 Friedman J: The real cause of obesity: it's not gluttony. It's genetics. Why our moralizaing misses the point. Newsweek Web Exclusive, September 9, 2009. http://www.thedailybeast. com/newsweek/2009/09/09/the-real-causeof-obesity.html.

47 Fairburn CG, Beglin SJ: Assessment of eating disorders: interview or self-report questionnaire? Int J Eat Disord 1994;16:363-370.

48 Moss-Morris R, Weinman J, Petrie KJ, Horne $\mathrm{R}$, Cameron LD, Buick D: The revised Illness Perception Questionnaire (IPQ-R). Psychol Health 2002;17:1-16.

49 Ajzen I: The theory of planned behavior. Organ Behav Hum Decis Process 1991;50:179-211.

50 Sanderson SC, Michie S: Genetic testing for heart disease susceptibility: potential impact on motivation to quit smoking. Clin Genet 2007;71:501-510.

51 Witte K, Cameron KA, McKeon JK, Berkowitz JM: Predicting risk behaviors: development and validation of a diagnostic scale. J Health Commun 1996;1:317-341. 
52 Robins RW, Hendin HM, Trzesniewski KH: Measuring global self-esteem: construct validation of a single-item measure and the Rosenberg self-esteem scale. Pers Soc Psychol Bull 2001;27:151-161.

53 Rosenberg M: Society and the Adolescent Self-Image. Princeton, Princeton University Press, 1965, p 326.

54 Persky S, Sanderson SC, Koehly LM: Online communication about genetics and body weight: implications for health behavior and internet-based education. J Health Commun 2013;18:241-249.

55 Wardle J: Understanding the aetiology of childhood obesity: implications for treatment. Proc Nutr Soc 2005;64:73-79.

56 Danielsdottir S, O’Brien KS, Ciao A: Anti-fat prejudice reduction: a review of published studies. Obes Facts 2010;3:47-58.

-57 Sanderson SC, Diefenbach MA, Streicher SA, et al: Genetic and lifestyle causal beliefs about obesity and associated diseases among ethnically diverse patients: a structured interview study. Public Health Genomics 2013;16:8393.
Ogden J, Flanagan Z: Beliefs about the causes and solutions to obesity: a comparison of GPs and lay people. Patient Educ Couns 2008;71: 72-78.

59 Molster C, Charles T, Samanek A, O'Leary P: Australian study on public knowledge of human genetics and health. Public Health Genomics 2009;12:84-91.

60 Wang C, Coups EJ: Causal beliefs about obesity and associated health behaviors: results from a population-based survey. Int J Behav Nutr Phys Act 2010;7:19.

61 Ashida S, Goodman M, Pandya C, Koehly LM, Lachance C, Stafford J, Kaphingst KA: Age differences in genetic knowledge, health literacy and causal beliefs for health conditions. Public Health Genomics 2011;14:307316.

62 Senior V, Marteau TM, Peters TJ: Will genetic testing for predisposition for disease result in fatalism? A qualitative study of parents responses to neonatal screening for familial hypercholesterolaemia. Soc Sci Med 1999;48: 1857-1860.
63 Segal ME, Polansky M, Sankar P: Predictors of uptake of obesity genetic testing among affected adults. Hum Genet 2007;120:641-652.

64 Segal ME, Polansky M, Sankar P: Adults' values and attitudes about genetic testing for obesity risk in children. Int J Pediatr Obes 2007;2:11-21.

65 Sanderson SC, Diefenbach MA, Zinberg R, Horowitz C, Smirnoff M, Zweig M, Streicher S, Jabs EW, Richardson LD: Willingness to participate in genomics research and desire for personal results among underrepresented minority patients: a structured interview study. J Community Genet 2013, E-pub ahead of print.

66 Meisel SF, Walker C, Wardle J: Psychological responses to genetic testing for weight gain: a vignette study. Obesity 2012;20:540-546.

67 Sanderson SC, Persky S, Michie S: Psychologi$\mathrm{cal}$ and behavioral responses to genetic test results indicating increased risk of obesity: does the causal pathway from gene to obesity matter? Public Health Genomics 2010;13:34-47.

68 United States Census Bureau: 2010 Census Data. http://2010.census.gov/2010census/ (last accessed March 20, 2012). 